\title{
Market Efficiency of Floating Exchange Rate Systems: Some Evidence from Pacific-Asian Countries
}

\author{
Osamah M. Al-Khazali ${ }^{a}$, Guillaume Leduc ${ }^{b}$, Chong S. Pyun ${ }^{c^{*}}$ \\ ${ }^{a}$ Department of Accounting and Finance, American University of Sharjah \\ ${ }^{b}$ Department of Mathematics and Statistics, American University of Sharjah \\ ${ }^{c}$ Department of Finance, University of Memphis
}

\begin{abstract}
$\underline{\text { Abstract }}$
This paper examines the random walk hypothesis (RWH) and the martingale difference hypothesis (MDH) for the Australian dollar and five Asian emerging currencies relative to three benchmark currencies. We use Wright's (2000) non-parametric procedure to test the RWH and Kuan and Lee's (2004) procedure to test the MDH. The results of Wright's tests and Kuan and Lee's test are adjusted for size distortion. The RWH is rejected for all currencies before and after the Asian crisis. The results of Kuan and Lee's test are consistent with the fact that the RWH is more stringent than the MDH. For the three testing periods, the MDH fails to reject the AUD. For all other currencies the MDH is rejected at least for one benchmark over two periods, indicating that the market efficiency in these markets have not significantly improved under the floating rate systems following the Asian financial crisis.
\end{abstract}

JEL Classification: F31, G14

Keywords: Efficiency of foreign exchange markets; Random walk,

Martingale difference hypothesis; and Emerging currency markets

*Corresponding author: Fogelman College of Business, the University of Memphis, Memphis, TN 38152. Ph: (901) 678-4645; Fax: (901) 678-0839; E-mail: cspyun@memphis.edu 


\section{Market Efficiency of Floating Exchange Rate Systems: Some Evidence from Pacific-Asian Countries}

\section{Introduction}

In the aftermath of the Asian currency crisis of 1997, many Asian emerging economies changed their exchange rate regimes from de facto pegs to floating systems. By most accounts, the exchange rate systems in these countries are still evolving within the broad framework of "managed" "free" or "independent float systems."1 The literature abounds with findings that nominal exchange rates generally follow a random walk and that most foreign exchange markets are at least weak-form efficient. ${ }^{2}$

In a weak-form efficient market, risk-adjusted excess return is unattainable. This is because the series of returns of exchange rate $s_{t}, s_{t-1}, s_{t-2}, \ldots$ is a martingale. Thus, by definition, price history does not help improve the forecast of future returns from its current level or trend.

In contrast to martingales, which are not necessarily Markov processes, random walks are Markovian. Thus the assumption underlying the random walk hypothesis is stronger than that of the martingale hypothesis, in that in addition to being a martingale, the expected value of $s t$ in a random walk depends only on the latest return $s_{t-1}$ as opposed to the whole history $s_{t-1}, \ldots s_{t-n}$, in the case of a martingale.

Testing the martingale and random walk hypotheses provide analysts with the benefits of the plausibility of stochastic economic models, which are of great interest to traders, academicians and, in particular, regulators at both national and multinational levels. Why? Both the martingale or the random walk property should preclude misalignments of foreign exchange

\footnotetext{
${ }^{1}$ Ee et al. (2003) allude that Singapore pursues a managed floating system. Ryoo (2001) and .the Bank of Korea webpage show that Korea pursued a managed floating until April 2002. The country's exchange regime afterward is said to be "free floating" or "independent floating. On the classification of "floating" regimes, see IMF (2006).

${ }^{2}$ Belaire-Franch and Opong (2005) provide a good survey on testing the random walk hypothesis.
} 
rate that can be exploitable by "noise" traders or speculators, both of whom heavily rely on technical analyses of trends and attendant reverting patterns of price changes. In a weak-form efficient model, future movements of foreign exchange are unpredictable from known past prices or trends. In this model, currency traders and speculators cannot beat the market by "noise trading", the well known trading technique which relies on technical analysis of trends, changes in market sentiment, advice of opinion leaders and statements of government officials. Yet, there are reports that such techniques are widely practiced in the interbank currency markets worldwide including East Asia, and that foreign exchange markets in many emerging economies are still inefficient. ${ }^{3}$

The purpose of our study is to investigate the weak-form market efficiency through random-walk and martingale behaviors of the Australian dollar and five Asian emerging market currencies - the Korean won, Malaysian ringgit, Singaporean dollar, Thai baht and Taiwanese dollar - before and after the Asian currency crisis of $1997 .{ }^{4}$ All currencies are studied in terms of their nominal rates relative to three benchmark currencies - the U.S. dollar, Japanese yen and euro. These three currencies are used as the benchmarks because of their credibility and influence on the region's trading patterns, which has become increasingly tied to the Japanese yen, Euro and Australian dollar. ${ }^{5}$ The Australian dollar is included, as it is fast becoming a major trading currency in the region (Bowman, 2005). The Chinese yuan and the Hong Kong dollar are excluded because the former is heavily controlled by the Chinese government while the latter pegged to the U.S. dollar under a currency board.

\footnotetext{
${ }^{3}$ See Neely, Weller and Ulrich (2009) for developed country currencies, and Lee, Gleason and Mathur (2001), Ahn et al. (2002) and Lee et al. (2004) for emerging country currencies.

${ }^{4}$ The Malaysian ringgit has been pegged to the U. S. dollar since the Asian financial crisis. See Figure 2.

${ }^{5}$ See Bowman (2005). Kearney and Muckley (2008) suggest that more than 40 percent appreciation of the U. S. dollar against the yen between 1995 and 1998 precipitated the Asian financial crisis. Kang and Wang (2002) report that with a 10 percent increase in the yen/dollar rate, Korea's export prices decline an average of 2.7 percent.
} 
Previous studies of the RWH focus on the least restrictive (weakest) form known as the RW-type III, which assumes that asset returns are linearly independent. By contrast, the MDH for asset returns denies the presence of any linear or non-linear combinations of past asset returns that could improve their forecastability. If an asset return follows a martingale difference process, then the returns become purely non-predictable. Besides testing the RWH using Wright's non-parametric VR test, we also employ the procedure of Kuan and Lee (2004) to test whether the currency markets in our sample follow a martingale difference process. Thus, our methodology for testing the weak-form efficiency of foreign exchange markets goes beyond previous research which is generally confined to testing the RWH under restrictive assumptions.

A fresh evaluation of the market efficiency of Pacific-Asian currencies, especially in terms of the U.S. dollar, yen and euro, is timely for several reasons. First, Asian trade and investment are increasingly linked beyond the U. S. dollar to include Japan, Europe and Australia (Kearney and Muckley, 2008). Second, the Asian financial crisis has revived active policy discussions by government official and academia in the region to devise mechanisms under which monetary and exchange rate cooperation among Asian countries is enhanced. Examples are the "Chiangmai initiative" by the seven ASEAN countries plus China, Japan and Korea, and the feasibility of integrating Asian currency markets under an optimum currency area (see Eichengreen and Park, 2004 and Mishara and Sharma, 2010). Third, the massive rise in dollar-denominated assets in the Asian countries' reserve accounts caused downward pressure on the U.S. dollar relative to the euro and frequent government interventions in the exchange markets. As a result, a realignment of currencies has taken place, with Asian foreign exchanges gaining strength against the dollar in response to the appreciation of the euro and yen (see Figures 1 and 2 for movements against the dollar and Euro, respectively). Fourth, there has been 
a development of active offshore derivative markets in the form of non-deliverable forward and non-deliverable option markets for Asian emerging country currencies (see Ma et al., 2004). These offshore markets will eventually form an important part of the network of Asian foreign exchange markets, and exchange rate policies of Australia and the five Asian emerging countries should be sustainable in terms of the world bench-mark currencies. Lastly, empirical findings on the efficiency of the Asian emerging market exchange rates have thus far been tentative and mixed in the few published studies we have reviewed.

The results of Wright's tests show that, after adjusting for size and multiplicity distortions, the RWH is rejected for all currencies before and after the Asian crisis. However, in market efficiency the RWH is more stringent than the MDH, and the results of Kuan and Lee's test reflect this. During the three periods only the AUD fails to reject the MDH, while the other currencies rejected the MDH against at least one benchmark over two periods.

The remainder of this paper is organized as follows. Section 2 provides a brief review of relevant literature. Section 3 discusses the data and Section 4 outlines the methodology. Section 5 presents the empirical findings. Section 6 concludes the paper.

\section{Related Literature}

The principal tools used for testing the efficiency of foreign exchange markets can be grouped into two categories; namely, time series examination of parity or alignment of exchange rates in models that include key macroeconomic variables like interest rates, prices and money supply; and time series examinations like the Lo and MacKinlay (1988) and Chow and Denning 
(1993) VR tests, the Kuan and Lee (2004) test based on moment conditions, unit root and cointegration tests, bootstrap tests, and ARIMA and GARCH processes. ${ }^{6}$

This paper focuses on the time series analysis of the exchange rates themselves with no additional exogenous independent variables. Two studies that address emerging Asian foreign exchange markets with additional analytical variables are noteworthy. Jeon and Seo (2003) examine the impact of the Asian financial crisis on the efficiency of foreign exchanges of Indonesia, Korea, Malaysia, and Thailand. Using unit root and cointegration procedures, they test market efficiency within-country and across-country over the pre- and post-crisis periods. Their results are consistent with across-country efficiency in all four markets. Another study that allows for the role of additional exogenous independent variables is Gau (2005), who uses intraday market volatility as the information variable in his periodic GARCH-based examination of the calendar anomalies of the Taipei foreign exchange market. He reports intraday seasonality and calendar effects in this market.

The use of VR tests for studying the RWH in foreign exchange rates of emerging markets is remarkably sparse, as compared to the use of the same econometric tool for examining the behavior of emerging stock markets. As Hoque, Kim and Pyun (2007) report, out of eighteen articles published on the RWH in emerging stock markets, all but two studies use Lo-MacKinlay, Chow-Denning or Wright VR tests. One possible reason for the paucity of VR tests when studying the efficiency of foreign exchange markets (as opposed to stock markets) may lie in the fact that the two markets are fundamentally different in their structures and modus operandi. In

\footnotetext{
${ }^{6}$ See, for example, Liu and He (1991), Urrutia (1992), Ajayi and Karemera (1996), and Lee, Pan and Liu (2001) for the Lo-MacKinlay VR test; Lima and Tabak (2005) for the bootstrap test; Cheung, Chin and Pascual (2005), and Kilian and Taylor (2003) for OLS and the exponential smooth transition autoregressive models, respectively; Baharumshah, Haw and Fountas (2005) for unit root tests; Jeon and Seo (2003) for cointegration tests; and Gau (2005) for periodic GARCH. Belaire-Franch and Opong (2005) also use the Wright procedure to test the behavior of the Euro against other major currencies.
} 
stock markets, governments seldom intervene as buyers or sellers. In foreign exchange markets, not only do governments intervene directly, but they also possess policy tools to modulate demand and supply forces in the currency market. In addition, official policy pronouncements could be quite different from what governments actually do in foreign exchange markets (Calvo and Mishkin, 2003). For example, an emerging economy may officially follow a floating regime but without being fully transparent on its precise policy targets or how the central bank intends to align its exchange value within the currency band. As McCauley (2008) points out, if we view the foreign exchange markets as being efficient, foreign exchange time series may be described by a nonstationary diffusion martingale process with uncorrelated increments.

Three recent papers use the VR tests to evaluate the behavior of foreign exchanges in emerging markets. Ajai and Karemera (1996) use the Lo-MacKinlay VR test to study the exchange rates of seven Asian emerging markets ${ }^{7}$. Their results reject the RWH. Using essentially the same testing procedure, Lee, Pan and Liu (2001) argue that many Asian and nonAsian currencies generally follow a random walk process. And on the basis of a bootstrap analysis, Lima and Tabak (2005) also report that several Asian and Latin American currencies are consistent with the RWH. Results reported by Lee, Pan and Liu (2001) and Belaire-Franch and Opong (2005) suggest that the contradictory evidence in the above studies on the random walk behavior of foreign exchange markets may lie in using the traditional VR test, which is particularly sensitive to conditional heteroscedasticity. Belaire-Franch and Opong demonstrate that the Wright non-parametric VR test presents a significant improvement over the traditional VR tests in this regard.

When asset returns follow a martingale difference process, the best forecast of tomorrow's return is simply today's return, and there is no combination (whether linear or non-

\footnotetext{
${ }^{7}$ The currencies are those of Hong Kong, Indonesia, Korea, Malaysia, Philippines, Taiwan and Thailand.
} 
linear) of previous returns that could improve the forecasts of future returns. Clearly, the martingale difference hypothesis has strong implications for whether asset returns behave according to market efficiency in the weak sense. Available evidence on this hypothesis is mixed. While Fong, Koh and Ouliaris (1997) and Dominguez and Lobato (2003) report supporting results in foreign exchange markets; Hong and Lee (2003) and Yilmaz (2003) do not.

\section{Data and Summary Statistics}

Our data are daily nominal exchange rates of the Australian dollar and five Asian currencies relative to the U.S. dollar (USD), the Japanese yen (JPY) and the Euro (EUR) from January 4, 1993 through December 31, 2005 (data source: http://fx.sauder.ubc.ca). The currencies under study are the Australian dollar (AUD), the Malaysian ringgit (MYR), the Singapore dollar (SGD), the South Korean won (KRW), the Taiwanese dollar (TWD), and the Thai baht (THB). The number of daily observations of individual currencies under study is approximately 3260 , with slight variations in the sample numbers attributable to different days of market closing.

While the official exchange rate regimes of the six countries under study are a matter of public record, as documented in their official homepages and various IMF publications, the ways in which their exchange regimes are actually administered has often been quite different from their official pronouncements. However, as is clear from Figures 1 and 2, it appears that the exchange regimes of these countries have witnessed a major change since the 1997 Asian financial crisis. Consequently, we divide our sample into two sub-samples: The first covers the period from January 1993 through November 1997 for all currencies (except for the Thai baht, where its first sub-sample ends in June 1997); and the second sub-sample spans the period from 
December 1998 through December 2005 for all currencies (except for the Thai baht, where its second sub-sample begins in July 1997). We perform our tests of the RWH and the MDH on the full period as well as separately on the two sub-periods.

\section{Insert Figures 1 and 2 about here}

Descriptive statistics for the daily exchange rates relative to the Euro are reported in Table 1. The skewness of daily exchange rates is positive for AUD, SGD and THB and negative for KRW, MLR and TWD. The positive skewness implies that the exchange rates are flatter to the right compared to the normal distribution. The kurtosis reported for each currency indicates that the distributions of the exchange rates have sharp peaks compared to the normal distribution. One general inference drawn from Table 1 is that the distributions of all currency series under study are not likely to be normal. In fact, Jarque-Bera's statistics suggest the presence of significant non-normality in the six exchange rates.

Insert Table 1 about here

As Figures 1 and 2 indicate, all six exchange rates show distinct downward spikes around 1997, corresponding to the timing of the Asian financial crisis. The descending spikes of the currencies are quite drastic in Figure 2 as compared to Figure 1, indicating that the currencies were on de facto pegs to the U.S. dollar prior to the crisis. These patterns contrast with the currency movements of the sample over the last two years, due to the appreciation of the Euro against the U.S. dollar.

\section{Methodology}

\subsection{The Wright Non-Parametric VR Test}

In this study, we use the VR test of Wright (2000) and the martingale difference sequence test of Kuan and Lee (2004), both of which are non-parametric, as opposed to widely used 
parametric VR models of the Lo and MacKinley (1989) or Chow and Denning (1993) variety. It should be noted that Lo-MacKinlay and Chow-Denning VR tests are asymptotic tests, whose sampling distributions are approximated based on their limiting distributions. Moreover, the sampling distribution of the VR statistic can be far from normal in finite samples, showing severe bias and right skew. These finite sample deficiencies may give rise to serious size distortions or low power, which can lead to misleading inferences. This is especially true when the sample size is not large enough to justify asymptotic approximations. As Deo and Richardson (2003) point out, the Lo-MacKinlay test, in particular, is inconsistent with respect to the variety of mean-reverting alternatives, where the limiting power function is bounded by a number less than one. Lee, Kim and Newbold (2004) find that RWH is often erroneously either rejected or affirmed by these VR tests. For instance, Kilian and Taylor (2003) support RWH and Liu and He (1991) reject it, while Yilmaz (2003) and Lee, Kim and Newbold (2004) partially support RWH. (See additional citations shown in footnote 5.)

Wright's (2000) nonparametric tests using sign and rank have two advantages over the Lo-MacKinlay and Chow-Denning tests when sample size is relatively small: (i) as the sign and rank tests have exact sampling distribution, there is no need to resort to asymptotic approximation and (ii) the tests may be more powerful than the conventional VR tests when the data are highly non-normal (Wright, 2000). ${ }^{8}$

To derive the non-parametric VR statistic based on ranks, Wright substitutes the time series used in the traditional Lo and MacKinlay test statistic with two linear transformations of the rank of the variable in question. Let $r\left(p_{t}\right)$ be the rank of $p_{t}$ among $p_{1}, p_{2}, \ldots, p_{n}$, where

\footnotetext{
8 Wright reports that "I take it as given that conventional variance-ratio tests are useful tests for serial dependence [as argued by Lo and MacKinlay (1989)]. If the sign-and rank-based tests are dominated in terms of their size and power properties by conventional variance-ratio tests, then they are of little interest to researchers. But if the signand rank-based tests have better size and power properties than the conventional variance-ratio tests in some plausible models, then it follows that these new tests are useful specification tests".
} 
$r_{1 t}=\frac{\left(r\left(p_{t}\right)-\frac{N+1}{2}\right)}{\sqrt{\frac{(N-1)(N+1)}{12}}}, r_{2 t}=\lambda^{-1}\left(\frac{r\left(p_{t}\right)}{(N+1)}\right)$, and $\lambda$ is the standard normal cumulative distribution function. We substitute $r_{1 t}$ and $r_{2 t}$ in place of $x_{t}$ in the Lo and MacKinlay tests statistics $\mathrm{z}_{1}$ and $\mathrm{z}_{2}$. Wright's rank statistics, $R_{l}$ (under homoskedasticity) and $R_{2}$ (under heteroskedasticity) are:

$$
\begin{aligned}
& R_{1}=\left(\frac{\frac{1}{N k} \sum_{t=k+1}^{N}\left(r_{1 t}+r_{1 t-1} \ldots \ldots . .+r_{1 t-k}\right)^{2}}{\frac{1}{N} \sum_{t=1}^{N} r_{1 t}^{2}}-1\right) \times\left(\frac{2(2 k-1)(k-1)}{3 k N}\right)^{-1 / 2} \\
& R_{2}=\left(\frac{\frac{1}{N k} \sum_{t=k+1}^{N}\left(r_{2 t}+r_{2 t-1} \ldots \ldots . .+r_{2 t-k}\right)^{2}}{\frac{1}{N} \sum_{t=1}^{N} r_{2 t}^{2}}-1\right) \times\left(\frac{2(2 k-1)(k-1)}{3 k N}\right)^{-1 / 2} .
\end{aligned}
$$

Wright provides another non-parametric test using the signs of the series instead of the ranks, resulting in $S_{1}$ and $S_{2}$. Specifically, for any series $y_{t}$, let $\omega\left(y_{t}, q\right)=1\left(y_{t}>q\right)-0.5$. Thus, $\omega\left(y_{t}, 0\right)$ is $1 / 2$ if $y_{t}$ is positive and $-1 / 2$ otherwise. Let $s_{t}=2 \omega\left(p_{t}, 0\right)=2 \omega\left(\varepsilon_{t}, 0\right)$, where $s_{t}$ is an iid series with zero mean and unitary variance. Each $s t$ is equal to 1 with a probability $1 / 2$ and is equal to -1 otherwise. The VR sign-based statistic using s1 is:

$$
S_{1}=\left(\frac{\frac{1}{N k} \sum_{t=k=1}^{N}\left(s_{t}+s_{t-1} \ldots .+s_{t-k}\right)^{2}}{\frac{1}{N} \sum_{t=1}^{N} s_{t}^{2}}-1\right) \times\left(\frac{2(2 k-1)(k-1)}{3 k N}\right)^{-1 / 2} .
$$

The quantity $S_{1}$ assumes a zero mean, but this assumption is relaxed for $S_{2}$ [see Wright (2000) for the derivation of $\mathrm{S}_{2}$ ]. Both $S_{1}$ and $S_{2}$ provide valid and exact tests even under conditional heteroskedasticity, although $S_{2}$ is more conservative. Wright shows that the rank-based test outperforms the sign-based test. However, both are more powerful than the traditional VR test.

Since we perform individual VR tests under a joint hypothesis of the random walk, results from the Wright test may be flawed by size distortions arising from sequential testing for 
different $k$ intervals. Following Belaire-Franch and Opong (2005), we mitigate these distortions by using the Sidack adjusted $p$-values.

\subsection{The Kuan and Lee Test}

Previous research suggests that foreign exchange rates may exhibit non-linear dependence, and thus many models that assume either i.i.d. (in cases of ARCH and GARCH) are inconsistent with uncorrelated increment which violates a martingale sequence (McCauley, 2009). As discussed in Section 2, a simple random walk process is a special case of the martingale process. The martingale process has generally been tested using information contained in the second moments of a process, and the property of the martingale difference sequence is known as mean-independence or conditional-mean-independence (Dominguez and Labato (2003). In this sense, tests of the MDH evaluate the empirical validity of the assumption implicit in the "technical" or "filter" rules that returns revert to their historical or time-varying means.

Kuan and Lee (2004) demonstrate that their test is more powerful than several other tests of $\mathrm{MDH}$, for their test is insensitive to the assumption of conditional homoskedasticity and requires a weaker moment condition. It should be pointed out that previous studies of RWH focus on the least restrictive (weakest) form known as the RW-type III, which assumes that asset returns are linearly independent. By contrast, $\mathrm{MDH}$ for asset returns denies the presence of any linear or non-linear combinations of past asset returns that could improve their forecastability.

\subsubsection{Martingale Test}

Arising from games of chance, a stochastic process $\left\{x_{t}\right\}$ is a martingale if it satisfies:

$$
E\left(x_{t+1} \mid x_{t}, x_{t-1}, \ldots\right)=x_{t},
$$


If $x_{t}$ represents the $\log$ of an asset price, then its first difference (return) behaves according to a martingale difference process if:

$$
E\left(\Delta x_{t+1} \mid x_{t}, x_{t-1}, \ldots\right)=0
$$

As already pointed, if asset returns follow a martingale difference process, the best forecast of tomorrow's return is simply today's return and there is no combination of previous returns that could improve the forecasts of future returns. Kuan and Lee (2004) propose a new procedure to test the martingale difference hypothesis (MDH). Among the virtues of Kuan and Lee's test is its insensitivity to the assumption of conditional homoskedasticity, and it requires a weaker moment condition. A brief account of the test follows.

Let $y_{t}, t=1,2, \ldots, T$ be a series of daily returns and let $\beta$ be the reciprocal of the sample standard deviation of the series $y$. Following similar notation to that of Kuan and Lee, define

$$
\begin{aligned}
& \varphi_{c}(y)=\frac{1}{1+\beta^{2} y^{2}} \\
& \varphi_{s}(y)=\frac{\beta y}{1+\beta^{2} y^{2}},
\end{aligned}
$$

and, for $k>1$ and $k<t \leq T$, define functions $\varphi_{c}(y, t-1, k)$ and $\varphi_{s}(y, t-1, k)$ recursively by

$$
\begin{aligned}
& \varphi_{c}(y, t-1, k)=\varphi_{c}(y, t-1, k-1) \varphi_{c}\left(y_{t-k}\right)-\varphi_{s}(y, t-1, k-1) \varphi_{s}\left(y_{t-k}\right) \\
& \varphi_{s}(y, t-1, k)=\varphi_{c}(y, t-1, k-1) \varphi_{s}\left(y_{t-k}\right)+\varphi_{s}(y, t-1, k-1) \varphi_{c}\left(y_{t-k}\right),
\end{aligned}
$$

where

$$
\begin{aligned}
& \varphi_{c}(y, t-1,1)=\varphi_{c}\left(y_{t-1}\right) \\
& \varphi_{s}(y, t-1,1)=\varphi_{s}\left(y_{t-1}\right) .
\end{aligned}
$$


If we then define

$$
\psi_{j}(y, t, k)=y_{t} \varphi_{j}(y, t-1, k) \text { for } j=c, s
$$

and, for a given $k$,

$$
\begin{aligned}
& \bar{\psi}_{j}=\frac{1}{T-k} \sum_{t=k+1}^{T} \psi_{j}(y, t, k) \text { for } j=c, s \\
& \hat{\sigma}_{j}^{2}=\frac{1}{T-k} \sum_{t=k+1}^{T}\left(\psi_{j}(y, t, k)\right)^{2} \text { for } j=c, s \\
& \hat{\sigma}_{c s}=\frac{1}{T-k} \sum_{t=k+1}^{T}\left(\psi_{c}(y, t, k) \times \psi_{s}(y, t, k)\right) \\
& J=\frac{T-k}{\hat{\sigma}_{c}^{2} \hat{\sigma}_{s}^{2}-\hat{\sigma}_{c s}^{2}}\left[\hat{\sigma}_{s}^{2} \bar{\psi}_{c}^{2}+\hat{\sigma}_{c}^{2} \bar{\psi}_{s}^{2}-2 \hat{\sigma}_{c s} \bar{\psi}_{c} \bar{\psi}_{s}\right],
\end{aligned}
$$

Then, under certain assumptions, Kuan and Lee show that $p$-values can be derived from $J \stackrel{D}{\rightarrow} \chi^{2}(2)$

\section{Empirical Results}

\subsection{Results for the RWH}

Under the null hypothesis that foreign exchange rates follow a random walk, the traditional variance ratios should equal to one. This paper uses instead Wright's (2000) more powerful non-parametric VR test based on ranks and signs. We compute the VR statistics (for multiples of 2, 5, 10, and 30 days) for the full sample period as well as for the pre- and postAsian financial crisis sub-periods. ${ }^{9}$

The results indicates that at least one estimate of the three VR statistics, $R_{l}(k), R_{2}(k)$ and $S_{l}(k)$ for lags $k=2,5,10$, and 30 are different from unity at least at the $10 \%$ level of significance for all currencies studied. Thus, whether the Euro, the USD or the JPY is used as the base

\footnotetext{
${ }^{9}$ The results for the Wright tests are available upon request.
} 
currency, the RWH is rejected for all six currencies under the assumptions of both homoskedasticity and heteroskedasticity over the full sample period. The RWH is similarly rejected for all six currencies over the pre-Asian financial crisis. As to the evidence for the postAsian financial crisis period, the results continue their rejection of the RWH, but only for the Asian currencies. In this second sub-period, the Australian dollar appears consistent with the RWH when measured in terms of the Euro and the Yen. This finding for the AUD accords well with the evidence reported by Belair-Franch and Opong (2005).

As mentioned earlier, Chow and Denning (1993) argue that VR statistics at differing intervals suffer from possible test-size distortions that could lead to upward biases in rejecting the RWH. Belaire-Franch and Opong (2005) further suggest that the deceptive rejection may be particularly higher for Wright's rank test under robust heteroskedasticity. Following BelaireFranch and Opong, we mitigate the effect of the test-size distortions using three alternative models. Specifically, we compute Wright's VR ranks and signs statistics for two $k$ values (2 and 5) when $\mathrm{N}=100$, three $k$ values (2, 5, and 10) when $\mathrm{N}=500$ and four $k$ values $(2,5,10$, and 30) when $\mathrm{N}=1000$. We then analyze the impact of these model changes on the empirical size of each individual test. We also conduct Monte Carlo simulations to estimate the rejection rates for Wright's VR tests at the 5\% significance level. In addition, we compute the Sidack-corrected $p$ values in order to alleviate the effect of possible correlations among the estimated statistics. Tables 2, 3 and 4 reports the Sidack-corrected $p$-values for Wright's test statistics for the full period, as well as for the pre- and post-Asian financial crisis sub-periods. The results of Wright's tests show that after adjusting for size distortion, the RWH is rejected for all currencies before and after the Asian crisis. 
Insert Tables 2, 3, 4

Note further that the results do not vary significantly when corrected for the effects of size distortions. For the pre-Asian financial crisis period, the corrected $p$-values are not markedly different from the results for the full period. Also consistent with our earlier findings, the corrected $p$-values for the post-Asian financial crisis period suggest rejection of the RWH for all currencies.

\subsection{Results for the $M D H$}

Similarly to examining the RWH, we test the MDH, by computing Kuan and Lee's $J(k)$ statistics for the full sample period, as well as for the pre- and post-Asian financial crisis sub-periods. Also for compatibility with the Wright test, the respective results from Kuan and Lee's test are computed for multiples of 2, 5, 10, and 30 days. The results we obtained for the full period are not consistent with the $\mathrm{MDH}$, as for each currency, the $J(k)$ statistics across the six currencies prove statistically significant for at least one value of $\mathrm{k}$, with respect to one or more of the benchmark currencies. ${ }^{10}$ Indeed, the degree of rejection of the MDH is stronger and at a higher frequency compared with the rejection of the RWH from the Wright test. With one exception, the verdict is the same over the post-Asian crisis period. The sole exception is the Australian dollar for which the MDH is not violated with respect to any of the three benchmark currencies. Thus, whether we focus on the RWH or the MDH, the Australian dollar seems to have achieved weak-form efficiency since the Asian crisis of the late 1990s. At least, such hypothesis cannot be rejected from the tests that we conducted and, certainly, it has achieved a higher degree of weak-form efficiency than the other currencies under study.

\footnotetext{
${ }^{10}$ Results are not reported but available upon request. We are reporting the results after adjusting $p$-values for size distortions.
} 
The results of Kuan and Lee's tests after adjusting for Sidack corrected $p$-values are reported in Table 5. The results show that AUD fails to reject the MDH for all period against all benchmarks however, for the other currencies, the MDH is rejected at least against one benchmark over two periods.

Insert Table 5

It should be noted that, without applying the Sidack corrected p-values, the MDH is rejected for all exchange rates under study over all periods against at least one benchmark, with the exception of the AUD after the Asian crisis and the MYR before.

\section{Concluding Remarks}

Our study tests the random walk and the martingale difference hypotheses for the Australian dollar and five Asian currencies - the Korean won, the Malay ringgit, the Singapore dollar, the Thai baht and the Taiwan dollar - in a time span bisected by the Asian financial crisis. We use Wright's (2000) non-parametric test to investigate the RWH and Kuan and Lee's (2004) test to investigate the MDH. The results of Wright's tests and Kuan and Lee's test are adjusted for size distortion. The RWH is rejected for all currencies before and after the Asian crisis. However, in market efficiency the RWH is more stringent than the MDH, and the results of Kuan and Lee's test reflect this. During the three periods, the MDH -and therefore weak-form efficiency- fails to be rejected for the AUD. However, for the other currencies, MDH and weakform efficiency are rejected, at least for one benchmark over two periods.

On balance, these findings are consistent with the conclusions of Ahn et al. (2002) and Ryoo (2001) for the Korean won and Bowman (2006) for the Australian dollar. Under an efficient asset pricing model, "noise traders" cannot beat the market and reap abnormal profits. 
However, Ahn et al. (2002) demonstrate that noise trading is active and profitable in the Korean won, and that the Korean currency has been both inefficient before and after the Asian crisis.

Central bank interventions in emerging foreign exchange markets have often been pronounced. This is particularly true for the period examined in this paper, during which the Euro has appreciated remarkably against the US dollar, resulting in massive shifts in many Asian countries away from the US dollar towards Euro-based assets. Despite these currency realignments and the purported changes in the exchange rate systems since the Asian financial crisis, the evidence we have obtained in this study suggests that the emerging Asian foreign exchange markets have not improved their efficiency under the floating rate regime. With the recent growth in offshore non-deliverable forward and option markets in many Asian currencies, an evaluation of the relative inter-country exchange efficiency seems a promising topic for future research. 


\section{References}

Ahn, C., Lee, E. B. and Suh, E. H., 2002. Noise trading in the Korean foreign exchange market: Some questionnaire evidence. Economic Paper, the Bank of Korea, 5. 133-155.

Ajayi, R. A., and Karemera, D., 1996. Variance ratio test of random walk in exchange rates: evidence from Pacific Basin Economies. Pacific Basin Finance Journal 4, 77-91.

Azad, A.S.M., 2009. Random walk and efficiency tests in the Asia-Pacific foreign exchange markets: Evidence from the post-Asian currency crisis data. Research in International Business and Finance 23, no. 3, 322-338.

Baharumshah, A. Z., Haw, C. T. and Fountas, S., 2005. A panel study on real interest rate parity in East Asian countries. Global Finance Journal 16, 69-85.

Baillie, R.T., McMahon, P.C., 1989. The Foreign Exchange Market: Theory and Econometric Evidence. Cambridge University Press, Cambridge, UK.

Belaire-Franch, J. and Contreras, D., 2011. Testing the Martingale Property of Exchange Rates: A Replication. Studies in Nonlinear Dynamics \& Econometrics, In Press.

Belaire-Franch J., and Opong, K. K., 2005. Some evidence of random walk behavior of Euro exchange rates using ranks and sings. Journal of Banking and Finance 29, 1631-1643.

Bowman, C., 2005. Yen block or koala bloc? currency relationships after the East Asian crisis," Japan and the World Economy, 17, 83-96.

Calvo, G. A. and Mishkin, F., 2003. The mirage of exchange regimes for emerging market Countries. Journal of Economic Perspectives 17, 99-118.

Cheung, Y. W., Chin, M. D. and Pascual, A. G., 2005. Empirical exchange rate models of the nineties: are any fit to survive? Journal of International Money and Finance 24, 1150-1175.

Chortareas, G., Jiang, Y. and Nankervis, J.C., 2010. The random-walk behavior of the Euro exchange rate. Finance Research Letters, In Press.

Chow, K. V. and Denning, K. C., 1993. A simple multiple variance ratio test. Journal of Econometrics 58, 385-401.

Debelle, G., Gyntelberg, J. and Plumb, M., 2006. Forward currency market is Asia: Lessons from the Australian experience. BIS Quarterly, September, 53-64.

Dominguez, W. M. and Lobato, I. N., 2003. Testing the Martingale different hypothesis: A consistent test for the martingale difference. Econometric Review 22. 4. 351-377. 
Ee, K. H., Robinson, E. and Lee, J., 2004. Managed floating and intermediate exchange rate system: The Singapore experience. MAS Staff Paper 37.

Eichengreen, B. and Park, Y. C., 2004. Why has there been less financial integration is Asia than in Europe. Working Paper, the Monetary Authority of Singapore.

Fong, W. M., Koh, S. K. and Ouliaris, S., 1997. Joint variance ratio tests of the martingale hypothesis for exchange rates. The Journal of Business and Economic Statistics 15, 51-59.

Gau, Y. F., 2005. Intraday volatility in the Taipei FX market. Pacific-Basin Finance Journal 13, 471-487.

Hong, Y. and Lee, T. H., 2003. Inference on predictability of foreign exchange changes via generalized spectrum and nonlinear time series models. Review of Economics and Statistics 85, 1048-1062.

Hoque, H. A., Kim, J. H. and Pyun, C. S., 2007. A comparison of variance ratio tests of random walk: A case of Asian emerging markets. International Review of Economics and Finance 16, 488-502.

International Monetary Fund, 2006. De Facto classification of exchange rate regimes and monetary framework, Statistics, December 22, 2006.

Japan Ministry of Finance, 2001. Exchange rate regimes fro emerging market economies. Discussion paper, Asia-Europe Finance Ministers Meeting, Kobe, Japan. January.

Jeon, B. N. and Seo, B., 2003. The impact of the Asian financial crisis on foreign exchange market efficiency: the case of East Asian countries. Pacific-Basin Finance Journal 11, 509-525.

Kang, S. and Wang, Y., 2002. Exchange rate pass-through in East Asia. Policy Analysis 02-09, Korea Institute of International Economic Policy.

Kearney, C. and Muckley, C. 2008. Can the traditional Asian US dollar peg exchange rate regime be extended to include the Japanese yen? International Review of Financial Analysis 17, 870-885.

Kilian, L. and Taylor, M. P., 2003. Why is it so difficult to beat the random walk forecast of exchange rate. Journal of International Economics 60, 85-107.

Kim, T. J. and Ryou, J. W., 2001. The optimal currency basket and the currency bloc in Asia. Bank of Korea Economic Papers 4, 194-216.

Kuan, C. and Lee, W., 2004. A new test of the martingale difference hypothesis. Studies in Nonlinear Dynamics \& Econometrics 8, Article 1. 
Lee, C. I., Gleason, K. C. and Mathur, I., 2001. Trading rule profits in Latin American currency spot rate. International Review of Financial Analysis 10, 135-156.

Lee, Y-S., Kim, T-H. and Newbold, P. 2004. Revisiting the Martingale hypothesis for exchange rates. Working Paper. University of Nottingham, UK.

Lee, C. I., Pan, M-S, and Liu, Y. A., 2001. On market efficiency of Asian foreign exchange rates: evidence from a joint variance ratio test and technical trading rules. Journal of International Financial Markets, Institutions and Money 11, 199-214.

Lee, K. H., Robinson, E. and Lee, J. 2004. Managed floating and intermediate exchange rate systems: the Singapore experience. MAS Staff Paper 37. Monetary Authority of Singapore.

LeRoy, S. F. 1989. Efficient capital markets and martingales. Journal of Economic Literature 27, $1583-1621$.

Lima, E. J. and Tabak, B. M., 2005. Testing the random walk hypothesis for emerging market exchange rates. Working Paper, Banco Central de Brasil.

Lo, A.W., Mackinlay, A.C., 1988. Stock market prices do not follow random walks: Evidence from a simple specification test. Review of Financial Studies 1, 41-66.

Lo, A., and MacKinlay, C., 1989. The size and power of variance ratio test in finite samples: A Monte Carlo investigation. Journal of Econometrics 40, 203-238.

Liu, C. Y. and He, J., 1991. A variance ratio test of random walk in foreign exchange rates. Journal of Finance 46, 773-785.

Ma, G., Ho, C. and MaCauley, R. N., 2004. The markets for non-deliverable forwards in Asian currencies. BIS Quarterly Review, 81-94.

Marey, P.S., 2004. Exchange rate expectations: controlled experiments with artificial traders. Journal of International Money and Finance 23, no. 2, 283-304.

McCauley, J. L., 2008. Nonstationaryity of efficient finance markets: FX markets evolution from stability to instability. International Review of Financial Analysis 17, 820-837.

McCauley, J. L., 2009. RCH and GARCH models vs. martingale of volatility of finance market returns. International Review of Financial Analysis 18, 151-153.

Mishra, R. K. and Sharma, C., 2010. Real exchange rate behavior and optimum currency area I Asia: Evidence from Generalized Purchasing Power Parity. International Review of Financial Analysis 19, 205-213.

Neely, C. J., Weller, P. A. and Ulrich, J. M., 2009. The adaptive markets hypothesis: Evidence from the foreign exchange market. Journal of Financial and Quantitative Analysis, 44, 467-488 
Ryoo, S., 2001. Exchange rate movement before and after free floating: efficiency and technical trading profitability. Bank of Korea Economic Papers 4, 160-176.

Smith, G., and Ryoo, H. J., 2003. Variance ratio tests of the random walk hypothesis for European emerging stock markets. European Journal o Finance 9, 290-300.

Urrutia, J., 1992. Variance ratio tests of random walk for foreign exchange rates. Economics Letters 38, 457-465.

Wright, J., 2000. Alternative variance ratio tests using ranks and signs. Journal of Business and Economics Statistics 18, 1-9.

Yang, J., Su, X., Kolari, K.W., 2008. Do Euro exchange rates follow a martingale? Some out-ofsample evidence. Journal of Banking and Finance 32, 729-740.

Yilmaz, K., 2003. Martingale property of exchange rates and central bank intervention. Journal of Business and Economics Statistics 21, 383-395. 
Figure 1: Asian Exchange Rates Relative to the Euro: 1993 - 2005
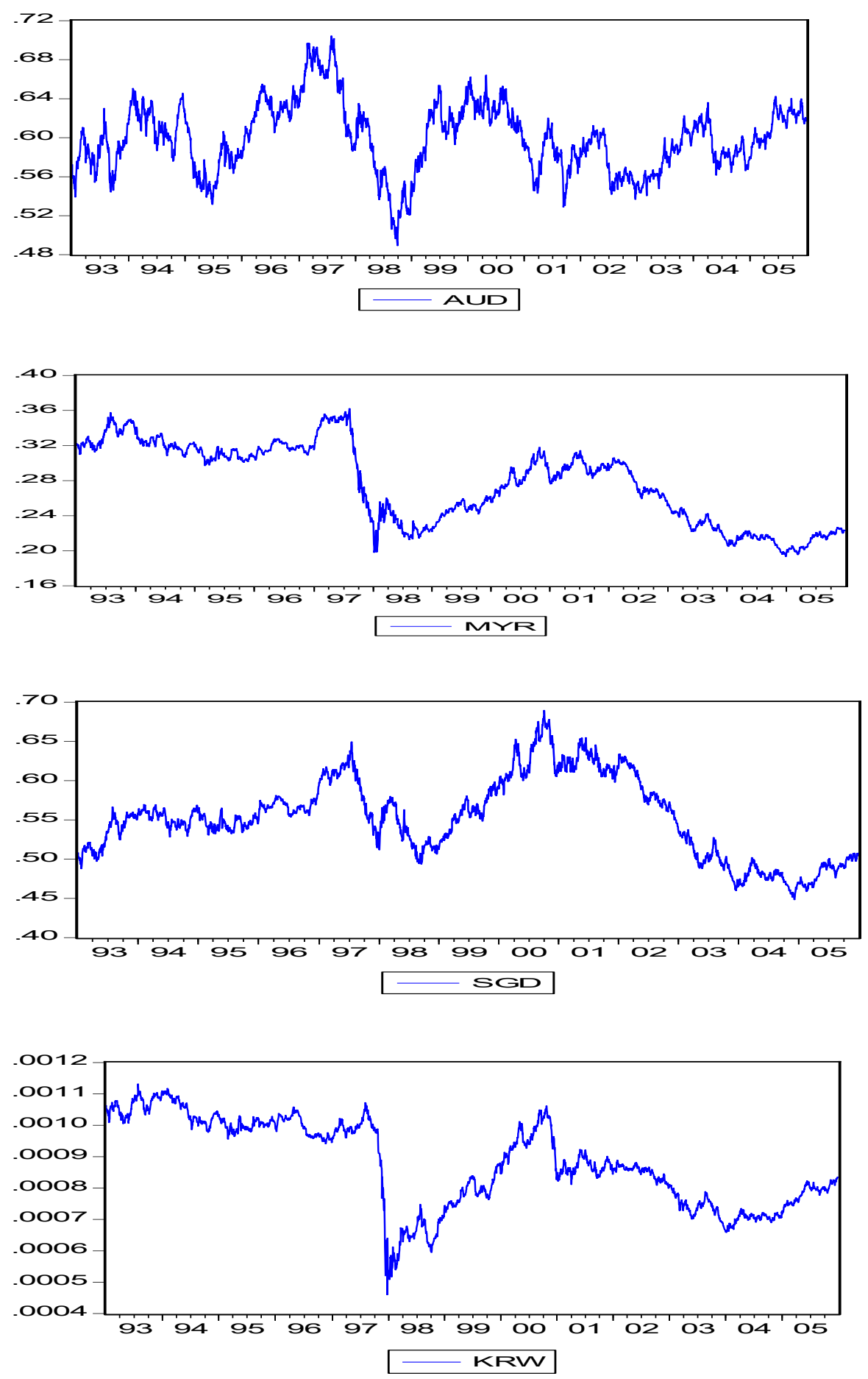

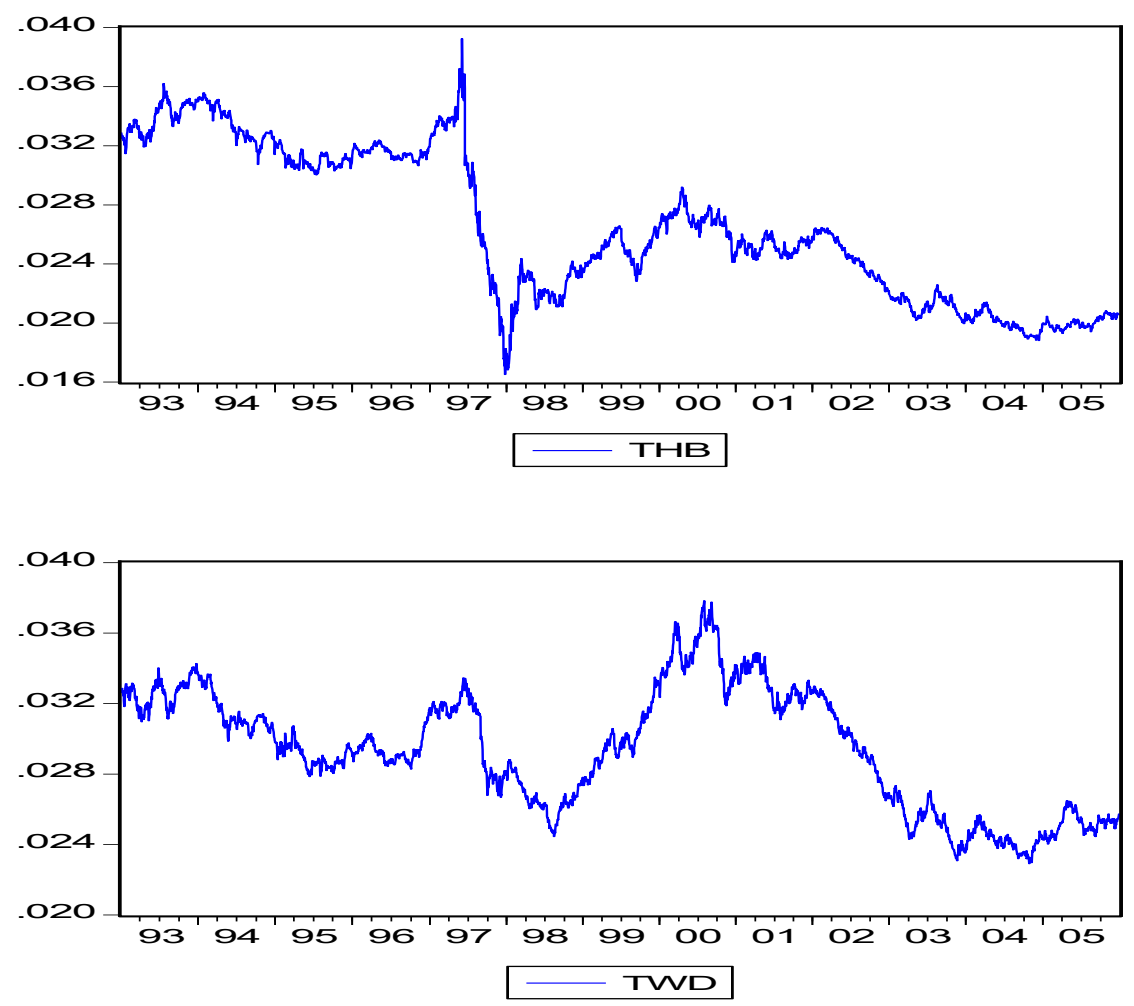

Figure 2: Asian Exchange Rates Relative to the USD: 1993 - 2005
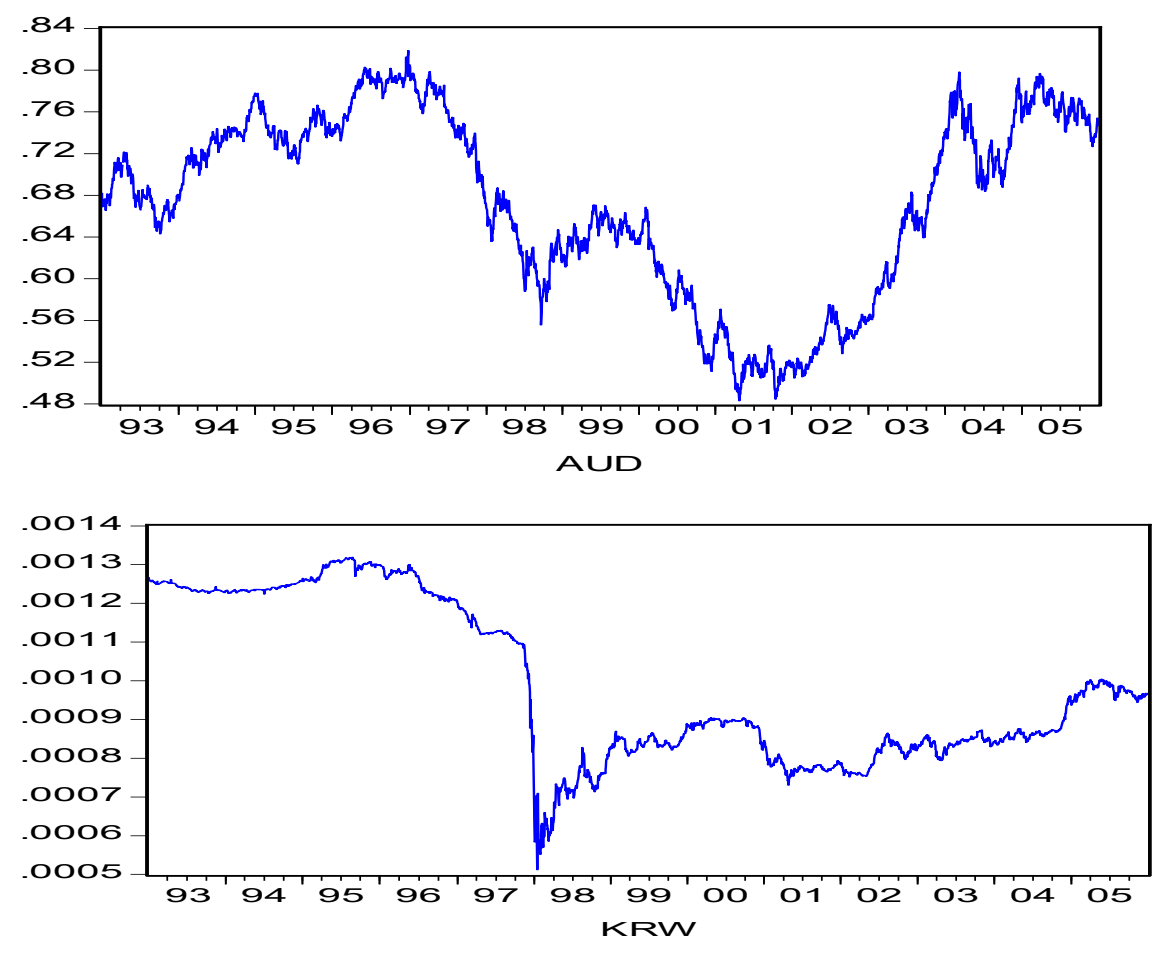

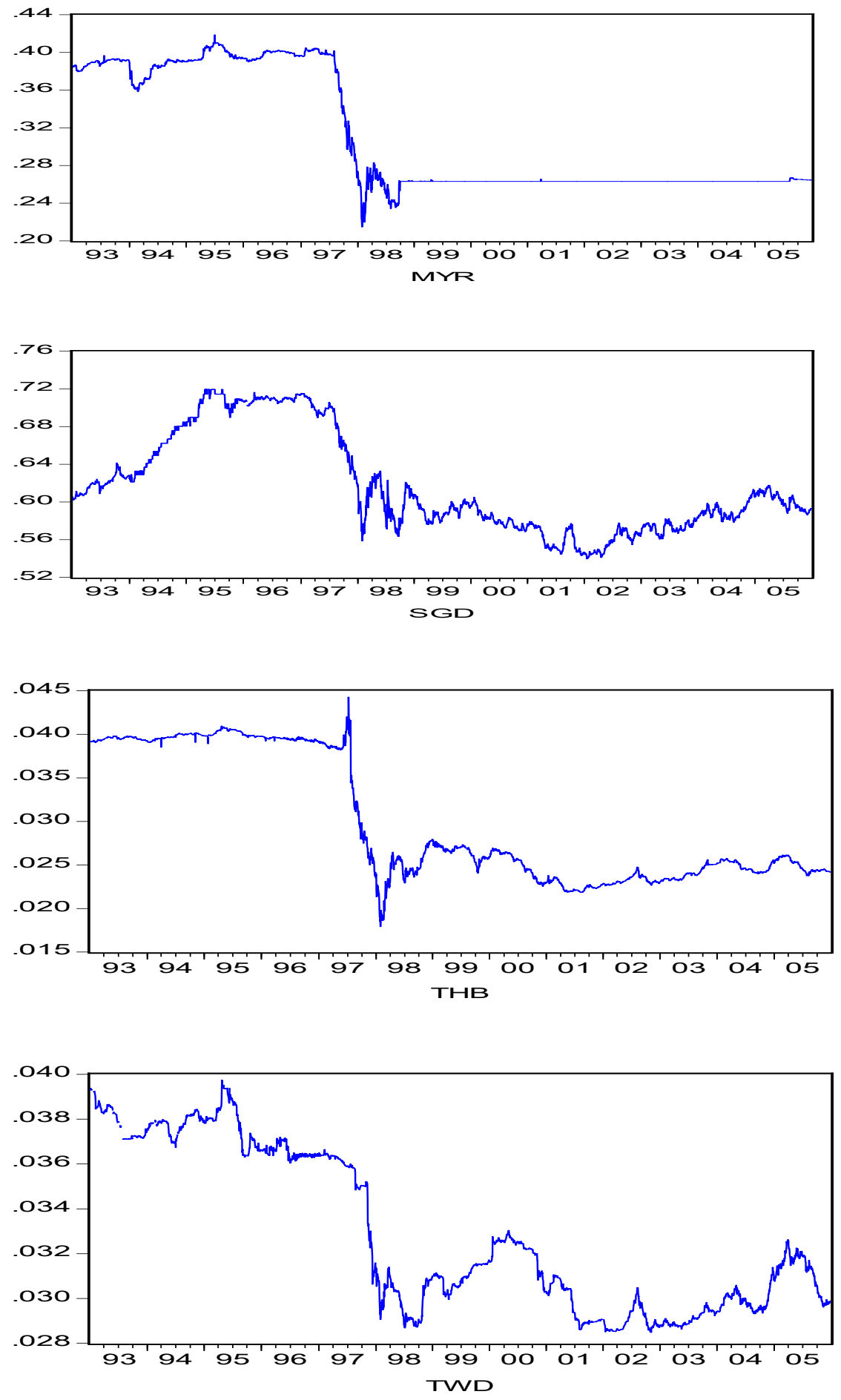
Table 1: Descriptive Statistics of Daily Data for the AUD and Five Asian Currencies Relative to the Euro (Sample Period: Jan.1993 - Dec. 2005)

\begin{tabular}{lcccccc}
\hline & AUD & KRW & MYR & SGD & THB & TWD \\
\hline Mean & 0.59928 & 0.000877 & 0.276494 & 0.553077 & 0.026457 & 0.029394 \\
Median & 0.59945 & 0.000868 & 0.285205 & 0.553710 & 0.025556 & 0.029433 \\
Maximum & 0.70428 & 0.001132 & 0.362332 & 0.689417 & 0.039231 & 0.037821 \\
Minimum & 0.48907 & 0.000460 & 0.193173 & 0.448290 & 0.016505 & 0.022917 \\
Std. Dev. & 0.03528 & 0.000139 & 0.045162 & 0.050303 & 0.005077 & 0.003359 \\
Skewness & 0.09542 & -0.229269 & -0.126928 & 0.135032 & 0.213644 & -0.007896 \\
Kurtosis & 3.00155 & 1.990434 & 1.692345 & 2.342040 & 1.716187 & 2.095127 \\
Jarq.-Bera & 4.95640 & 167.3119 & 241.4668 & 68.83718 & 249.1348 & 111.4582 \\
Probability & 0.08390 & 0.000000 & 0.000000 & 0.000000 & 0.000000 & 0.000000 \\
Sum & 1957.25 & 2.864845 & 903.0300 & 1806.350 & 86.40725 & 96.00039 \\
Sample & & & & & & \\
$\quad$ Size & 3266 & 3266 & 3266 & 3266 & 3266 & 3266 \\
\hline
\end{tabular}


Table 2: Wright's VR Test Results for the RWH with Sidack-Corrected p-values (The Full Period: Jan. 1993 - Dec.2005)

\begin{tabular}{|l|l|l|l|l|l|l|}
\hline & AUD & KRW & MYR & SGD & THB & TWD \\
\hline $\boldsymbol{R}_{\boldsymbol{I}}$ & $0.072^{*}$ & $0.073^{*}$ & $0.067^{*}$ & $0.022^{* *}$ & $0.067^{*}$ & $0.058^{*}$ \\
\hline $\boldsymbol{R}_{\boldsymbol{L}}$ & $0.069^{*}$ & $0.078^{*}$ & $0.085^{*}$ & $0.043^{* *}$ & $0.093^{*}$ & $0.087^{*}$ \\
\hline $\boldsymbol{S}_{\boldsymbol{I}}$ & $0.057^{*}$ & $0.067^{*}$ & $0.064^{*}$ & $0.033^{* *}$ & $0.072^{*}$ & $0.051^{*}$ \\
\hline
\end{tabular}

\begin{tabular}{|l|l|l|l|l|l|l|}
\hline & AUD & KRW & MYR & SGD & THB & TWD \\
\hline $\boldsymbol{R}_{\boldsymbol{I}}$ & $0.061^{*}$ & $0.083^{*}$ & $0.072^{*}$ & $0.031^{* *}$ & $0.057^{*}$ & $0.081^{*}$ \\
\hline $\boldsymbol{R}_{\boldsymbol{2}}$ & $0.051^{*}$ & $0.081^{*}$ & $0.065^{*}$ & $0.042^{* *}$ & $0.083^{*}$ & $0.067^{*}$ \\
\hline $\boldsymbol{S}_{\boldsymbol{I}}$ & $0.071^{*}$ & $0.072^{*}$ & $0.064^{*}$ & $0.056^{*}$ & $0.062^{*}$ & $0.061^{*}$ \\
\hline
\end{tabular}

Yen-based

\begin{tabular}{|l|l|l|l|l|l|l|}
\hline & AUD & KRW & MYR & SGD & THB & TWD \\
\hline $\boldsymbol{R}_{\boldsymbol{1}}$ & $0.071^{*}$ & $0.056^{*}$ & $0.071^{*}$ & $0.032^{* *}$ & $0.061^{*}$ & $0.056^{*}$ \\
\hline $\boldsymbol{R}_{\boldsymbol{2}}$ & $0.091^{*}$ & $0.067^{*}$ & $0.082^{*}$ & $0.041^{* *}$ & $0.091^{*}$ & $0.059^{*}$ \\
\hline $\boldsymbol{S}_{\boldsymbol{I}}$ & $0.087^{*}$ & $0.066^{*}$ & $0.054^{*}$ & $0.035^{* *}$ & $0.069 *$ & $0.068^{*}$ \\
\hline
\end{tabular}

Notes: This table reports the Sidack-adjusted $p$-values corresponding to the four $\mathrm{k}$ values.

$R_{1}$ and $R_{2}$ are the rank-based statistics and $S_{1}$ is the sign-based statistic, respectively.

An * indicates significance at the $10 \%$ level, while an** indicates significance at the $5 \%$ level. 
Table 3: Wright's VR Test Results for the RWH with Sidack-Corrected p-values (The Pre-Asian Crisis Period: Jan.1993 - Nov. 1997)

\begin{tabular}{|l|l|l|l|l|l|l|}
\hline & AUD & KRW & MYR & SGD & THB & TWD \\
\hline $\boldsymbol{R}_{\boldsymbol{I}}$ & $0.062^{*}$ & $0.083^{*}$ & $0.087^{*}$ & $0.032^{* *}$ & $0.057^{*}$ & $0.058^{*}$ \\
\hline $\boldsymbol{R}_{\boldsymbol{2}}$ & $0.039^{* *}$ & $0.068^{*}$ & $0.075^{*}$ & $0.033^{* *}$ & $0.083^{*}$ & $0.081^{*}$ \\
\hline $\boldsymbol{S}_{\boldsymbol{I}}$ & $0.047^{* *}$ & $0.077^{*}$ & $0.061^{*}$ & $0.035^{* *}$ & $0.062^{*}$ & $0.058^{*}$ \\
\hline
\end{tabular}

\begin{tabular}{|l|l|l|l|l|l|l|}
\hline & AUD & KRW & MYR & SGD & THB & TWD \\
\hline $\boldsymbol{R}_{\boldsymbol{I}}$ & $0.071^{*}$ & $0.081^{*}$ & $0.072^{*}$ & $0.021^{* *}$ & $0.067^{*}$ & $0.083^{*}$ \\
\hline $\boldsymbol{R}_{\boldsymbol{2}}$ & $0.041^{* *}$ & $0.057^{*}$ & $0.065^{*}$ & $0.062^{*}$ & $0.093^{*}$ & $0.077^{*}$ \\
\hline $\boldsymbol{S}_{\boldsymbol{I}}$ & $0.061^{*}$ & $0.062^{*}$ & $0.044^{* *}$ & $0.066^{*}$ & $0.042^{* *}$ & $0.041^{* *}$ \\
\hline
\end{tabular}

Yen-based

\begin{tabular}{|l|l|l|l|l|l|l|}
\hline & AUD & KRW & MYR & SGD & THB & TWD \\
\hline $\boldsymbol{R}_{\boldsymbol{I}}$ & $0.031^{* *}$ & $0.046^{* *}$ & $0.071^{*}$ & $0.042^{* *}$ & $0.071^{*}$ & $0.066^{*}$ \\
\hline $\boldsymbol{R}_{\boldsymbol{2}}$ & $0.081^{*}$ & $0.077^{*}$ & $0.082^{*}$ & $0.061^{*}$ & $0.094^{*}$ & $0.079^{*}$ \\
\hline $\boldsymbol{S}_{\boldsymbol{I}}$ & $0.067^{*}$ & $0.056^{*}$ & $0.051^{*}$ & $0.055^{*}$ & $0.059^{*}$ & $0.058^{*}$ \\
\hline
\end{tabular}

Notes: This table reports the Sidack-adjusted $p$-values corresponding to the four $\mathrm{k}$ values.

$R_{l}$ and $R_{2}$ are the rank-based statistics and $S_{I}$ is the sign-based statistic, respectively.

An * indicates significance at the $10 \%$ level, while an** indicates significance at the $5 \%$ level. 
Table 4: Wright's VR Test Results for the RWH with Sidack-Corrected $p$-values (The Post-Asian Crisis Period: Dec.1998 - Dec.2005)

\begin{tabular}{|l|l|l|l|l|l|l|}
\hline & AUD & KRW & MYR & SGD & THB & TWD \\
\hline $\boldsymbol{R}_{\boldsymbol{I}}$ & $0.092^{*}$ & $0.033^{* *}$ & $0.037^{* *}$ & $0.032^{* *}$ & $0.077^{*}$ & $0.088^{*}$ \\
\hline $\boldsymbol{R}_{\boldsymbol{L}}$ & $0.079 *$ & $0.058^{*}$ & $0.065^{*}$ & $0.063 *$ & $0.091^{*}$ & $0.077 *$ \\
\hline $\boldsymbol{S}_{\boldsymbol{I}}$ & $0.077^{*}$ & $0.087 *$ & $0.044^{* *}$ & $0.043^{* *}$ & $0.082^{*}$ & $0.041^{* *}$ \\
\hline
\end{tabular}

\begin{tabular}{|l|l|l|l|l|l|l|}
\hline & AUD & KRW & MYR & SGD & THB & TWD \\
\hline $\boldsymbol{R}_{\boldsymbol{1}}$ & $0.031^{* *}$ & $0.063^{*}$ & $0.042^{* *}$ & $0.045^{* *}$ & $0.054^{*}$ & $0.091^{*}$ \\
\hline $\boldsymbol{R}_{\boldsymbol{2}}$ & $0.061^{*}$ & $0.074^{*}$ & $0.055^{*}$ & $0.052^{*}$ & $0.093^{*}$ & $0.077^{*}$ \\
\hline $\boldsymbol{S}_{\boldsymbol{1}}$ & $0.078^{*}$ & $0.062 *$ & $0.044^{*}$ & $0.066^{*}$ & 0.072 & $0.064^{*}$ \\
\hline
\end{tabular}

Yen-based

\begin{tabular}{|l|l|l|l|l|l|l|}
\hline & AUD & KRW & MYR & SGD & THB & TWD \\
\hline $\boldsymbol{R}_{\boldsymbol{1}}$ & $0.061^{*}$ & $0.066^{*}$ & $0.041^{* *}$ & $0.062^{*}$ & $0.071 *$ & $0.046^{* *}$ \\
\hline $\boldsymbol{R}_{\boldsymbol{2}}$ & $0.081^{*}$ & $0.077^{*}$ & $0.062^{*}$ & $0.061^{*}$ & $0.092^{*}$ & $0.069 *$ \\
\hline $\boldsymbol{S}_{\boldsymbol{I}}$ & $0.082^{*}$ & $0.046^{* *}$ & $0.044^{*}$ & $0.055^{*}$ & $0.059 *$ & $0.064^{*}$ \\
\hline
\end{tabular}

Notes: This table reports the Sidack-adjusted $p$-values corresponding to the four $\mathrm{k}$ values.

$R_{I}$ and $R_{2}$ are the rank-based statistics and $S_{I}$ is the sign-based statistic, respectively.

An * indicates significance at the $10 \%$ level, while an** indicates significance at the $5 \%$ level. 
Table 5: Kuan and Lee's Test Result for the MDH with Sidack-Corrected p-values

\begin{tabular}{|c|c|l|l|l|l|l|}
\hline \multicolumn{7}{|c|}{ Full Period: Jan 1993 - Dec 2005 } \\
\hline Benchmark/Currency & AUD & \multicolumn{1}{|c|}{ KRW } & \multicolumn{1}{|c|}{ MYR } & SGD & THB & TWD \\
\hline EUR & 0.211 & 0.949 & $0.042^{* *}$ & 0.136 & 0.337 & $0.093^{*}$ \\
\hline USD & 0.578 & $0.005^{* * *}$ & 0.304 & 0.343 & 0.315 & $0.001^{* * *}$ \\
\hline JPY & 0.137 & 0.172 & 0.733 & $0.039^{* *}$ & 0.636 & $0.079^{*}$ \\
\hline \multicolumn{7}{|c|}{ Pre-Asian Crisis Period: Jan.1993 - Nov. 1997 } \\
\hline EUR & 0.663 & 0.361 & 0.661 & 0.705 & $0.070^{*}$ & 0.786 \\
\hline USD & 0.363 & $0.099^{*}$ & 0.831 & 0.380 & $0.018^{* *}$ & 0.417 \\
\hline JPY & 0.343 & 0.790 & 0.432 & $0.035^{* *}$ & 0.219 & 0.104 \\
\hline \multicolumn{7}{|c|}{ Post-Asian Crisis Period: Dec.1998 - Dec.2005 } \\
\hline EUR \\
\hline USD & 0.636 & 0.682 & $0.051^{*}$ & 0.322 & 0.286 & 0.181 \\
\hline JPY & 0.409 & $0.004^{* * *}$ & 0.136 & 0.479 & $0.001^{* * *}$ & $0.002^{* * *}$ \\
\hline
\end{tabular}

Notes: This table reports the Sidack-adjusted $p$-values corresponding to the four $\mathrm{k}$ values. An * indicates significance at the $10 \%$ level, an** indicates significance at the $5 \%$ level and an $* * *$ indicates significance at the $1 \%$ level 